\title{
CORRIGENDUM
}

\section{Market-Level Implications of Regulating Forest Carbon Storage and Albedo for Climate Change Mitigation - CORRIGENDUM}

\section{Aapo Rautiainen, Jussi Lintunen, and Jussi Uusivuori}

https://doi.org/10.1017/age.2018.8, Published by Cambridge University Press, August 2018

The authors of Rautianen, Lintunen and Uusivuori (2018) report some minor errors in the original article: radiative forcing is reported in the wrong units at several points in the text and figures. These errors do not affect the results or validity of the analysis. The correct version of the text is given below.

\section{Page 252, text in first paragraph:}

In the second externality pricing scheme (here after, constant prices) we assume a constant interest rate (5 percent) and constant SCC and SCF values (18.96 €/tCO2 and $328.41 € / \mathrm{nWm}^{-2} \mathrm{yr}$, respectively) that correspond to the values given for the year 2015 in the changing prices scheme.

\section{Page 252, text in last paragraph:}

At the age zero, the albedo of a treeless one hectare stand contributes 2.46 $\mathrm{nWm}^{-2}$ to global radiative forcing (Fig. 2). The albedo of a hectare of mature dense forest contributes contributes $2.77 \mathrm{nWm}^{-2}$ (Fig. 2). Valued at $328.41 €$ $\left(\mathrm{nWm}^{-2} \mathrm{yr}\right)^{-1}$ (in 2015 , see Fig. 1 ), the social cost of the warming power of the young stand is $807 € \mathrm{yr}^{-1} \mathrm{ha}^{-1}$. The corresponding value for mature forest is $909 € \mathrm{yr}^{-1} \mathrm{ha}^{-1}$. Thus, the difference between the social cost of open shrub and mature forest is $102 \mathrm{€yr}^{-1} \mathrm{ha}^{-1}$.

In addition, in Figure 1, the correct unit of the right vertical axis of central panel should be $€\left(\mathrm{nWm}^{-2} \mathrm{yr}\right)^{-1}$. The unit of vertical axis of the third panel should be $\mathrm{t}_{\mathrm{CO} 2}\left(\mathrm{nWm}^{-2} \mathrm{yr}\right)^{-1}$. 
In Figure 2 the unit of vertical axis should be $\mathrm{nW} \mathrm{m}^{-2}$.

In Figures 5, 6, 7 and 8a the fourth panel on the right (on all rows), the unit of vertical axis should be $n W m^{-2} h^{-1}$.

\section{Reference}

Rautianen, Lintunen and Uusivuori (2018) Market-Level Implications of Regulating Forest Carbon Storage and Albedo for Climate Change Mitigation. Agricultural and Resource Economics Review 47(2), 239-281. https://doi.org/10.1017/age.2018.8 